\title{
Maximally Intuitive, Minimally Evidenced: Universal cognitive biases as the basis for supernatural beliefs
}

\author{
Aiyana K. Willard \\ Centre for Culture and Evolution, \\ Brunel University London \\ Corresponding Author: aiyana.willard@brunel.ac.uk \\ Hugh Turpin \\ Centre for the Study of Social Cohesion, \\ School of Anthropology and Museum Ethnography, \\ University of Oxford \\ Adam Baimel \\ Department of Psychology, Health and Professional Development, \\ Oxford Brookes University
}

Words: 5520 (excluding abstract and references) 


\section{Abstract}

What explains the ubiquity of religions across time and space, and why do these supernatural belief systems seem to have so much in common? Many cognitive scientists of religion have proposed that cross-cultural patterns in religious belief are, at least in part, the indirect result of reliably developing and otherwise adaptive features of the human mind. These 'cognitive bias' theories propose that religion is a by-product of universal mental architecture. We see similar beliefs recur in unrelated cultural and historical contexts because of biases in how we perceive and interpret the word, and how we remember concepts. This chapter reviews the evidence, merits, and limitations of such theories. In so doing, the chapter addresses the most influential of the cognitive bias theories: the proposed relationships between various religious beliefs and Theory of Mind, anthropomorphism, dualism, teleological reasoning, and minimally counterintuitive concepts. We address both the strengths and shortcomings of these theories in explaining religious belief and suggest where we can go from here.

Keywords: Religion, cognitive biases, anthropomorphism, mind-body dualism, teleology, minimally counterintuitive 


\section{Why are cognitive biases important to understanding religion?}

Many features of religion, such as ritual practice and the belief in supernatural agents, are widely shared across religions (Tylor, 1871). What might explain the cross-cultural recurrence of these focal elements of religious systems? Early researchers in what became the 'cognitive science of religion' proposed that in order to explain the universality of religion, a new general theory of religion that considered religion's evolutionary origins was necessary (Boyer, 1994; Guthrie, 1980; Lawson \& McCauley, 1990). According to this view, the everyday functioning of the human mind makes supernatural/religious reasoning intuitively appealing or a "path of least resistance for our cognitive systems" (p. 1039, Boyer, 2008). This intuitive appeal was not claimed to be adaptive, but rather a by-product of otherwise adaptive functions (Atran \& Norenzayan, 2004; Kirkpatrick, 1999). This early work led to an examination of variants of religious beliefs with the goals of establishing their common, or universal, features and identifying their cognitive foundations. Research focused on the ways in which our minds perceive and process information that could give rise to religious-like beliefs. If these beliefs are intuitively supported, then they may have a selective advantage on the cultural marketplace (Sperber, 1996). Intuitively supported beliefs would appear with similar features around the world, and be more likely to survive and persist across generations (Atran \& Norenzayan, 2004).

This claim that the foundations of religion were cognitive launched a new era of looking at religion as universal and focusing on its common traits across our species (Sørensen, 2005; C. White, 2021). The key question at the centre of this cognitive and evolutionary revolution was identifying the specific cognitive processes and/or systems that made our species so prone to supernatural reasoning. One such process is mind perception, or Theory of Mind (ToM) - the ability to ascribe mental states (e.g., thoughts, beliefs, desires, 
emotions, and/or knowledge) to others. Though this ability clearly evolved for understanding other people and social learning, we do not limit our use of ToM to other humans. We use it to reason about a wide array of animals, objects, weather, and supernatural agents. This overuse, or misapplication, of ToM has been linked to many of the cognitive biases thought to underly religious belief (Willard et al., 2020; Willard \& Norenzayan, 2013), such as anthropomorphism (Guthrie, 1993, 1996) - the tendency to see non-human things as human; mind-body dualism (Bloom, 2005, 2007) - the tendency to see minds as separate and not reducible to physical bodies; and teleological reasoning (Kelemen, 1999a, 2004) - the tendency to see things as being intentionally made for a function or purpose.

Another major by-product theory is minimally counterintuitiveness. ( $\mathrm{MCl}$; Boyer, 2001). $\mathrm{MCl}$ theory suggests that religious ideas are more memorable because they violate core ontological categories - described as innate or reliably developing expectations we have for certain categories of things. They are, in essence, exceptions to our most deeply held rules about the world. The claim is that the things we see in religions, like talking animals or ghosts, persist and spread because they violate our intuitions about the world and therefore stand out in our memories. Other by-product theories we will not discuss pertain to behavioural features of religion such as ritual (e.g. Boyer \& Liénard, 2007). Here, we focus on the relationship between cognitive biases and religious beliefs. These theories have been particularly influential in this domain, and ritual is dealt with elsewhere (Whitehouse, this volume).

These cognitive by-product accounts of religion suggest that religious content is constrained by, and succeeds because of, aspects of our evolved cognitive architecture. That being said, the relationship between any specific content of lived religions and cognitive biases is ambiguous at best. What these biases intend to explain is the tendency for some 
broad types of supernatural beliefs to be ubiquitous across religious traditions (e.g., the existence of ghosts or spirits, or creationist myths) rather than the more particularistic features of specific religious beliefs (e.g., the trinity, or that cows are sacred). Even with this caveat, these theories are supported by a varying quality of empirical evidence. Many require updating with current developments in our understanding of human cognitive and cultural capacities. We will discuss each major theory in turn, including the evidence that supports them and the challenges they face, before discussing some of the ways forward from here.

\section{Theory of mind}

The link between supernatural agent beliefs and Theory of Mind (ToM) is clear: Gods, ghosts, and spirits are believed to have minds (i.e., capable of thoughts, beliefs, and desires); you need to be able to reason about minds in general to reason about supernatural minds (Gervais, 2013). At the same time, the relationship between measures relevant to ToM and religiosity are inconsistent (Jack, 2016; Lindeman et al., 2015). When found, this relationship is small; perhaps because it is indirect. Individuals more prone to considering the mental states of others are potentially also more prone to related cognitive biases such as anthropomorphism, mind-body dualism, and teleology (C. J. M. White, Willard, et al., 2021; Willard et al., 2020; Willard \& Norenzayan, 2013). These tendencies may lead to higher rates of religious belief, not differences in ToM directly.

To better understand this, we may need to consider which aspects of ToM are implicated in the perception of supernatural minds. These minds are not like human minds. They have powers, abilities, or knowledge beyond what we expect from normal human minds. Supernatural minds are often disembodied, meaning most supernatural agents lack many of the embodied cues we use to determine the mental states of people, such as facial 
expressions, posture, and gaze. This leaves us nothing but our imaginations, hallucinations, and what we believe are supernatural actions in the world, with which to understand a god's mind. Luhrmann (2012) describes how Vineyard evangelical Christians infer God's mental states from fortunate or unfortunate events encountered in daily life. They also learn to perceive some of their own thoughts as divine interjections. Cases such as this suggest culturally acquired and effortful practices for manipulating ToM plays more of a role than baseline variation in capacities for mentalizing.

These differences also create problems in how we measure ToM in this type of research. Like most psychological constructs, our ability to perceive and reason about other people's minds is measured indirectly through what we expect the various types of resulting behaviours and abilities will be. Tests of adult theory of mind measure things like the willingness to empathise and socialise with others (mentalizing; Baron-Cohen \& Wheelwright, 2004), or our accuracy in reading emotion from facial cues (Baron-Cohen et al., 2001). It is not clear these are the same aspects of ToM that allow us to think about supernatural agents.

Other research has shown an inverse relationship between autism, which included deficits in ToM and religious beliefs (Norenzayan et al., 2012), but this also might not be straight forward. Autistic populations can and do have rich relationships with invisible, imaginary, and supernatural agents, but these agents are idiosyncratic agents of their own making (Visuri, 2012, 2020). These invisible agents may be easier for people with autism to understand because they remove the complexities of navigating emotion recognition and other sensory stimuli involved in deciphering the mental states of humans (Visuri, 2018). This can be reconciled if deficits in ToM impact the cultural transmission of religious belief, rather than the ability to perceive and reason about invisible agents. Without the socially learned 
component of belief, we would expect most supernatural believers to do what these autistic samples do: create their own individual supernatural beings.

\section{Anthropomorphism}

Anthropomorphism is the tendency to project human mental states on non-human animals, objects, events, etc. Within the cognitive science of religion, it was first championed by Stuart Guthrie $(1993,1996)$, although discussions on the role of anthropomorphism within Christianity date to much earlier (Feuerbach, 1841; Hume, 1779). Guthrie's observation was that we tend to see human forms everywhere, and often these form religious in nature (e.g. Huffpost, 2017). We assume that a human-like agent is behind the rustling of leaves or bumps in the night (Barrett, 2004). This tendency should trigger a sense that these things have human-like minds we can interact with. This over perception of agents leads to belief in supernatural agents.

This idea is given evolutionary backing through error management theory (see Haselton \& Buss, 2000). Error management holds that when you are uncertain you should err on the side of whatever is more fitness relevant, in this case the detection of agents (Guthrie, 1996). When you hear a rustling in the trees or see a face in the clouds, caution (and evolutionary fitness) dictates you should assume it is an agent because agents are dangerous. If you are wrong there is very little cost. On the other hand, if you don't detect an agent that is there, the cost could be your life. The theory thus posits that people will be biased to interpret ambivalent cue in the environment as the product of agency. This 'module' was dubbed the Hypersensitive (or Hyperactive) Agency Detection Device (HADD; Barrett, 2000, 2004).

There are several issues with this theory. First, and rather importantly, there is no convincing empirical evidence that we do over detect agents in this manner, and not for lack of trying (Andersen, 2017). Second, there does not seem to be any plausible neurological basis 
for the existence of a HADD (Lisdorf, 2007). Third, agency detection may not be what we need to explain the existence of supernatural minds. A HADD assumes that reasoning about agents is automatic and not cognitively taxing, but it is not clear this is true if we are reasoning about that agent's mind, rather than simply perceiving it as alive. Though we can reason about selfdirected motion and simple goals effortlessly (Csibra et al., 1999), reasoning about mental states is costly enough to inhibit our ability to do other reasoning tasks while we are doing it (Jack et al., 2013). If you are standing in a crowded room it is easy to know that other people in that room are alive and have basic goals, but if you tried to think about what was going on in people's minds you would not be able to focus on more than a couple people at a time, and doing so would make it hard to track anything else in the room.

Andersen (2017) re-framed the detection problem as one of predictive coding - we over detect agents based on our prior expectation of their presence. This means we are likely to think a bump in the night is a ghost when we are already wary of ghosts. Though likely accurate, it does not solve the problem of how we come to believe in supernatural agents in the first place (Willard, 2017). Though it is effective at explaining the anecdotes about rustling leaves and bumps in the night, it requires pre-existing belief. Even with all of this, Guthrie's observation that people routinely believe in human-like agents that are not human is clearly true. We do anthropomorphise all sorts of things, including randomly moving dots on a screen (Tremoulet \& Feldman, 2000), anime pillows (Galbraith, 2019), and of course supernatural agents.

Other theories of anthropomorphism have addressed this phenomenon using a motivational theory of anthropomorphism (Epley et al., 2008). Waytz et. al (2010) looked at when and why we might see human-like minds in non-human things. The answers are twofold: 1) when we are lonely and want other minds around, and 2) when we can't use other 
causal reasoning systems (e.g., folk physics) to predict the behaviour of something. Motivational theories may help solve some of the problems with detection-based theories of anthropomorphism. People see additional human-like agents in the world because doing this fulfils a need or allows us to feel like we can solve otherwise difficult problems.

\section{Mind-Body dualism}

Mind-body dualism as a cognitive bias is the idea that humans intuitively see minds as separate and not reducible to bodies. This tendency is believed to be the basis for our ability to conceive of and believe in ghosts, souls, and other disembodied supernatural agents (Bloom, 2005, 2007). This intuition is based in evidence that we process information on mental states and physical states with two different systems in the brain creating the sensation that they are fundamentally separate (Damasio, 1994). Indeed, these systems are not only separate, but mutually inhibitory (Jack et al., 2013). When we think about minds, our ability to think about physical objects and their properties is diminished.

Intuitive dualism fits easily with some of our basic experiences of the world. It is very difficult to conceptualise your mind, or the thing that makes you you, as nothing more than a combination of your nervous system and the chemical and electrical signals that stimulate it. Because of this, the idea that you mind could leave your body and then return is easy to understand and requires much less explanation than a claim like your bones or nervous system could leave and then return. Many people find the material origin of the mind deeply uncomfortable to think about. It has also become one of the most intractable topics in philosophy of mind (i.e. the 'hard problem' of consciousness; e.g. Chalmers, 1996).

As well as a clear neurological foundation, mind-body dualism also has a substantial amount of empirical research behind it. Much of this research comes out of developmental psychology looking at how children conceive of minds versus bodies (Leslie, 1994), and the 
afterlife (i.e., what happens to our minds/bodies after death; Bering \& Bjorklund, 2004). There is enough work in this domain to make reviewing it beyond the scope of this chapter. Overall, this literature suggests that young children do conceptualise minds as separate from bodies (Bloom, 2005). Looking across cultures, Chudek et. al (2018) used a body switching paradigm to demonstrate that children in Canada and Fiji could easily intuit that a mind could move from one body to the other and the identity and goals of that agent would move with the mind. Other research conducted in Madagascar (Astuti \& Harris, 2008), Vanuatu (WatsonJones et al., 2016), and Brazil (Cohen \& Barrett, 2008), has shown some distinction between minds and bodies or souls and bodies. This is supported by a large ethnographic literature on things like spirit possession (Lewis, 2003). Slingerland and Chudek (2011) showed dualist concepts were common in pre-Qin (pre-221 BCE) Chinese texts, suggesting dualism is not a recent cultural invention.

Even with this, mind-body dualism as an intuitive bias for religion has not gone unchallenged. An alternative non-dualistic account of afterlife beliefs is provided by Hodge (2008), who argues that deities and spirits are almost always conceptualised as embodied (albeit in a non-ordinary way), and that our intuitions about post-mortem continuation rest on our inability to eliminate deceased others from our cognitive social registries, rather than difficulties conceptualising the extinction of our own minds. More recently, Barlev and Shtulman (2021) have offered several other critiques. These include that young children can have a difficult time representing deities without some physical traits (Shtulman, 2008), and inconsistencies in how people separate the psychical and mental traits of the dead (e.g., Watson-Jones et al., 2016). Though there is validity to these critiques, we find their proposed solution for explaining the widespread nature of this tendency, a memory bias for minimally counterintuitive concepts, unconvincing (seem minimally counterintuitive section below). 
These critiques do raise some important issues about how intuitive dualism has been characterized in the literature. Dualism as the belief that minds and bodies are completely and intractably separate seems an oversimplification. This discussion on 'mind', and how 'minds' are distinguished from 'souls' (e.g. Richert \& Harris, 2008), comes from a particular cultural context that is not universal. Cultural learning can play a large role in how exactly the category of the mind is delineated (Lillard, 1997, 1998; McNamara et al., 2019; Willard \& McNamara, 2019). The differences in beliefs about what traits survive death may reflect actual differences in how people from different cultures think about minds.

Additionally, the quality that belongs to a mind or a body are unlikely to be clearly separate in people's minds. Hunger is a good example here, and one were we see a lot of ambiguity in the data. Hunger as purely physiological body-relevant process may not be obvious on first principles. Hunger impacts our thinking, motivations, goals, and desires, as much as it does our physiology. Many cultures refer to disembodied spirits who nevertheless hunger; in Japanese folklore for instance, 'Gaki' are the souls of the greedy deceased who have been afflicted with incessant hunger for noxious items such as excrement or corpses. Putting these physiological states in the category of mind does not necessarily contradict mind-body dualism as a basic intuition.

It also does not follow that because we have an intuition that makes it easy to understand disembodied minds, that all supernatural agents, or even all understandings of the dead, would involve disembodied minds. Cultural learning will play a role here too. For example, Hindu deities can be embodied in statues of that deity (all statutes, all at once), as well as existing elsewhere or everywhere. Embodied versions of the Gods are bathed, dressed, and fed on a regular basis. This type of multi-bodied but also disembodied supernatural agent demonstrates the flexibility of how we think about minds and bodies. 
Variation across human cultures may be large, but the underlying similarities still suggest a basis in some kind of shared cognitive architecture.

\section{Promiscuous Teleology}

Teleology is the tendency to describe the existence of things by the purpose they have come to serve rather than their naturalistic causal origins. An example would be saying a tree exists to give us shade rather than it exists because it grew from a seed. This teleological explanation makes sense only if the tree was intentionally planted for shade, but not if the tree grew naturally. People tend towards the teleological explanation in both cases, suggesting an over generalization of beliefs about intentionality (Kelemen, 1999b; Kelemen \& Rosset, 2009).

Promiscuous teleology was introduced as a foundational bias for creationist beliefs, or more generally the tendency to see things in the world as being made by an intentional agent, by Kelemen (2004). Kelemen suggests that this intuition is based in our ability to understand artifacts. We treat most things in our environment as though an intentional mind made them for some purpose, and if we examine their affordances, we can understand that purpose. The most familiar example of this logic is Paley's (1802) watchmaker argument: if we found a watch in nature we would assume that someone designed it because of its complexity. How can we look at the complexity of the natural world and not assume that it was similarly designed?

Research on this concept has gone a long way to show that teleology is a default way of thinking - something we can override but that still remains as a bias just under the surface. Children readily apply teleological reasoning to all sorts of things (Kelemen, 1999a), and adults make teleological errors when they are otherwise cognitively taxed (Kelemen \& Rosset, 2009). Scientists can inadvertently adopt a teleological stance towards the natural world when they 
are under time pressure (Kelemen et al., 2013), and people with Alzheimer's are more prone to promiscuous teleology (Lombrozo et al., 2007). In both cases, people revert back to teleological reasoning when they are too cognitively constrained to inhibit this response in favour of a more accurate one.

Intuitive creationism is not the only way that teleology has been represented in the literature. One other is the 'just world' hypothesis (e.g. Lerner \& Montada, 1998; Johnson, 2016), namely the idea that certain recurring religious beliefs around surveillance, punishment, and reward are based on the moralistic pan-human intuition that people always 'get what they deserve'. Intuitive teleology has also been proposed as an underlying explanation for the commonly held belief that there is a purpose, fate, or meaning to life (e.g. Banerjee \& Bloom, 2014a, 2014b). The distinction between the tendency to see one's life as purposeful and the tendency to see things in the world as having a purpose is not always clearly articulated in the literature, though research suggests a small positive relationship between the two (Willard et al., 2020; Willard \& Norenzayan, 2013). Still, the degree to which people see their lives as having been intentionally designed like a hammer or pencil remains unclear.

Within the teleology literature, there remains a need for more cross-cultural research. This tendency towards promiscuous teleology has been found in Chinese samples (Rottman et al., 2017), but this still represents only a tiny slice of human cultural diversity. More work needs to be done in other cultures before we can confidently suggest this bias is widespread or make inferences about the precise role of teleology in religious beliefs.

\section{Minimally Counterintuitive Content}

Minimally counterintuitive $(\mathrm{MCl})$ theory is a different type of cognitive bias. Rather than suggesting that our perception of the world is biased in certain ways, $\mathrm{MCl}$ theory 
proposes a memory advantage for supernatural content can explain the proliferation of religion across human cultures (Boyer, 1994, 2001). The basics of this theory are that: 1) we have a reliably developing cognitive system that provides us with inferential knowledge about physical, biological, and mental states (referred to as ontological categories); 2) concepts and stories that are minimally counterintuitive, or minimally violate these ontological categories, are more memorable; 3) religious ideas contain such violations; and 4) this memory advantage explains the proliferation of religious concepts around the world (see Purzycki \& Willard, 2016)

There is a fair amount of research on the memory effects of the $\mathrm{MCl}$ bias, but results are inconsistent. Early experimental work looked at $\mathrm{MCl}$ bias in lists of $\mathrm{MCl}$ or non- $\mathrm{MCl}$ alien artifacts embedded in a story (Boyer \& Ramble, 2001), and looked for $\mathrm{MCl}$ and non- $\mathrm{MCl}$ concepts in Native American stories (Barrett \& Nyhof, 2001). There are 9 experiments across these two papers that all show greater memory for $\mathrm{MCl}$ content above intuitive and bizarrebut-not-counterintuitive content, but the sample sizes in these experiments are notably small. While one has a sample of 81 , most have sample sizes in the 20 s and a few as low as 18. This makes it difficult to judge the validity of these effects.

Other research has found somewhat different results. Upal and colleagues, found memory effects for $\mathrm{MCl}$ items, but only if the items were unexpected (Upal, 2010; Upal et al., 2007). When $\mathrm{MCl}$ items were put into a context that would make them expected, such as framing the stimuli as science fiction or the contents of a dream, the memory effect disappeared. This context effect would also likely apply to religious stories, where $\mathrm{MCl}$ type concepts are necessarily common if $\mathrm{MCl}$ theory is correct. Norenzayan and colleagues (2006) found a different memory effect. Their bias was for increased recall of intuitive items in a list that contained only a minimal number of $\mathrm{MCl}$ items. The $\mathrm{MCl}$ items themselves were 
forgotten. This, if generalized, would suggest that $\mathrm{MCl}$ concepts disappear from stories over time, and the memory effect for intuitive items vanishes with them.

$\mathrm{MCl}$ memory effects have been found in children (Banerjee et al., 2013). These effects, like prior studies (Boyer \& Ramble, 2001), were driven by breaches of intuitiveness (giving an object an impossible trait, like making it invisible or able to float) rather than transfers (giving something a trait from another category, such as giving a mountain a mind). If true, then ghosts - as people without bodies - might be more memorable, but animism and superhuman minds are unlikely to make the cut. Even the effect for ghosts is only plausible if we argue that mind-body dualism, which explains this same phenomenon with better evidence, is counterintuitive rather than intuitive.

This existing evidence only examines one part of $\mathrm{MCl}$ theory, the memory effect, while ignoring the other components. Additional problems arise when we look beyond memory. The ontological categories in $\mathrm{MCl}$ theory - which are human, animal, plant, artefact, and natural object (see Baillargeon \& Carey, 2012; Carey, 2009) - require a type of modularity that is difficult to reconcile with out more recent conceptions of how our brains are organized. Though the strict modularity (Fodor, 1983) argument is often dropped from rationales of $\mathrm{MCl}$ theory, it may actually be required for this theory to work. Without this, our knowledge systems should be able accommodate new concepts like ghosts and spirits in the same way we can update our reliably developing numeracy (see Xu et al., 2005) to accommodate number lines and calculus. Upal's (2010) context effects suggest updating is indeed what happens. A memory effect disappears when this content becomes expected. For this bias to explain the spread and maintenance of religious beliefs, our basic expectations about these ontological categories could not be updated with experience and 
learning in a way that allows $\mathrm{MCl}$ content become familiar and unsurprising (Purzycki \& Willard, 2016).

The final pillar of this theory is the idea that religious content is commonly $\mathrm{MCl}$. This has been primarily supported by anecdotal examples rather than a systematic evaluation. In the few places where systematic evaluations have been undertaken, findings are again inconsistent. Research that has looked across stories such as fairy tales (Barrett et al., 2009; Norenzayan et al., 2006) and Roman Prodigies (Lisdorf, 2004) has suggested that stories with minimal amounts ${ }^{1}$ of minimally counterintuitive content are more popular, but this does not speak to the commonness of these concepts within religion. Gibbon (2008) examined $\mathrm{MCl}$ content in Turkish sermons and shows that counterintuitive elements appear minimally within sermons, but only two counterintuitive items were identified: God as all-knowing and as all-perceiving. Both of these have been found to be routinely misremembered when people recall religious stories, due to their unintuitiveness (Barrett \& Keil, 1996). Purzycki (2013) examined spirit master beliefs in Tyva and found that $\mathrm{MCl}$ content was rare. Instead, people described spirit masters as counter-schematic or bizarre - a three-legged camel, a fish scaled bull, or a woman missing one breast. They are unusual examples of a category but would not meet the criteria of $\mathrm{MCl}$. Finally, memorability does not equate to belief and/or commitment (Willard et al., 2016). People know about and remember Zeus without belief in Zeus (Gervais \& Henrich, 2010).

We are left with the observation that religious concepts are a bit bizarre or strange and may sometimes qualify as $\mathrm{MCl}$. The category of $\mathrm{MCl}$ itself seems somewhat hard to

\footnotetext{
${ }^{1}$ This relates to another finding we have not fully discussed. As well as items themselves having minimal rather than maximal violations of intuitive ontologies for the memory bias to exits, stories containing them are also claimed to be more memorable when there are a minimal ( 2 or 3 ) rather than maximal (more than 3 ) numbers of these minimally counterintuitive elements (Banerjee et al., 2013; Norenzayan et al, 2006).
} 
justify as anything but an extension of counter-schematic or bizarre ideas. Ff a memory bias exists, it seems to be quite fragile (Purzycki \& Willard, 2016). At the same time, the idea that supernatural content is counter-schematic or bizarre does seem to be an important one. Across cultures, non-natural or unusual things are given additional importance and often additional powers with a frequency that would suggest some type of cognitive bias. What we are lacking is a good explanation of why this is the case.

\section{Successes, shortfalls, and where we go from here}

The seeming parsimony of cognitive bias theories provide intuitively compelling explanations for the ubiquity and similarity of religious beliefs in distinct cultural contexts. These theories propose accounts of how religious belief 'got started' in the distant past but are often underspecified. The basic observations still ring true - the universality of religious beliefs across human cultures, and the similarities found in these beliefs, suggest that some set of reliable cognitive functions underly them. At the same time, many of the theories explaining these things seems out of date with current thinking. For example, Visuri's (2018) work on supernatural agent beliefs in people with autism suggests that many of the assumptions about the cognitive capacities needed to represent invisible agents may be wrong. Issues with popular theories like HADD and $\mathrm{MCI}$ memory biases raise further problems suggesting that some of the commonly accepted reasons for the existence and spread of religions in human cultures may lack evidence or simply be implausible. In truth, we may know very little about how to answer these questions about the near universality of certain religious concepts.

Beyond issues with the cognitive mechanisms in individual theories, there are issues with the scope of what these theories can explain. Though it has been put forward that these 
biases can largely explain the existence of religion (e.g. Barrett, 2004, 2008), its clear that a consideration of cultural content is needed to explain why people adopt specific beliefs and not others (Gervais et al., 2011; Gervais \& Henrich, 2010), or why people believe highly implausible content at all (Whitehouse, 2004, 2021; Willard et al., 2016). At the same time, how these biases interact with culture and cultural evolutionary processes is not well understood (Purzycki \& McNamara, 2016; C. J. M. White, Baimel, et al., 2021). Work that has looked at this, has suggested that cultural context may substantially modify the impact of these biases (e.g., Richert et al., 2017). For example, individual difference in motivated anthropomorphism has been found to be a negative predictor of belief in God among Christians, but a positive predictor of belief in God among the non-religious (Willard et al., 2020). If anthropomorphism is used as an explanation for otherwise unexplainable happenings, as the motivated anthropomorphism theory suggests, then this may be because Christianity already offers a suitable explanation and other types of anthropomorphic explanations are not needed. Those without this belief system may still be using anthropomorphic explanations to suggest the existence of some type of god.

The more prominent account that biases as can lead to the existence and proliferation of supernatural content, and cultural evolution can shape this content into full-fledged religious traditions (see Gervais et al., 2011), may also be incomplete. If we lose the idea that supernatural content simply automatic, what is missing here is a reasonable explanation for when and why this content is generated in the first place. This may be motivated by the need to explain, predict, or manipulate something in the world, but there may be other possibilities too. More attention paid to when and where supernatural beliefs are used may help us better understand why supernatural beliefs are being generated, and why certain biased perceptions are being utilized. 
A quick survey of beliefs around the world would suggest that several common beliefs are not yet well accounted for within cognitive bias theories. These include a variety of beliefs about human supernatural powers (e.g. witchcraft, psychic powers, evil eye), divination (e.g. astrology, I Ching, tarot), supernatural beliefs about physical spaces, forces, or designs (e.g. feng sui, vastu shastra, sacred geometry) and many more. Some recent work has begun to address the widespread nature of shamanism (Singh, 2018) and witchcraft (Singh, 2019), but much more work on topics like these is needed. Recent work by Hong and Henrich (2021) has suggested certain supernatural beliefs may be much more empirically motivated than is often thought. By looking at historical records of Chinese rainmaking rituals, they demonstrate that decisions that these rituals work and which to use are based on observational evidence. Some rituals are likely to coincide with rain by chance alone, and some will do so frequently. When the probabilities of coincidental temporal relationships are ignored, this gives evidence of a ritual's effectiveness. The tendency to report successes over failures makes them seem even more effective. These are the same sorts of biases that can lead us to over select for, and support, un-replicable research in science.

Crucially, research in this domain has to confront the problem of reliably detecting the signal of these biases amidst the effects of thousands of years of cultural evolution and the ever-accelerating process of cross-cultural influence. This is not necessarily cause for despair. Much progress could be made in generating new theories by exploring beyond supernatural agent beliefs to explain why we, as a species, are drawn to supernatural beliefs as ways to explain, predict and manipulate the world we live in, and the other people in it. If there is nothing special about religion, as by-product theories suggest, looking beyond the confines of traditional 'supernatural beliefs' and examine how these theories relate to other unevidenced beliefs may also help us find the signal in the noise. Does overattributing agency 
contribute to the tendency to see malevolent design behind geopolitics? Could intuitive dualism explain the popularity of the transhumanist conviction that our 'selves' will one day be separated from our bodies and digitally uploaded? It may turn out that researching these perceived oddities may lead us to a better understanding of how we explain, predict, and manipulate the world not just within the domain of religion, but also more generally.

\section{References}

Andersen, M. (2017). Predictive coding in agency detection. Religion, Brain \& Behavior, 36(3), 1-6. https://doi.org/10.3389/fpsyg.2011.00395

Astuti, R., \& Harris, P. L. (2008). Understanding Mortality and the Life of the Ancestors in Rural Madagascar. Cognitive Science: A Multidisciplinary Journal, 32(4), 713-740. http://doi.wiley.com/10.1080/03640210802066907

Atran, S., \& Norenzayan, A. (2004). Religion's evolutionary landscape: counterintuition, committment, compassion, communion. Behavioral and Brain Sciences, 27, 713-770. https://doi.org/10.1017/S0140525X04000172

Baillargeon, R., \& Carey, S. (2012). Core cognition and beyond: The acquisition of physical and numerical knowledge. In S. M. Pauen (Ed.), Early childhood development and later outcome. (pp. 33-65). Cambridge University Press.

Banerjee, K., \& Bloom, P. (2014a). Why did this happen to me? Religious believers and nonbelievers teleological reasoning about life events. Cognition, 133(1), 277-303. http://dx.doi.org/10.1016/j.cognition.2014.06.017

Banerjee, K., \& Bloom, P. (2014b). “Everything Happens for a Reason”: Children's Beliefs About Purpose in Life Events. Child Development, 86(2), 503-518. 
http://doi.wiley.com/10.1111/cdev.12312

Banerjee, K., Haque, O. S., \& Spelke, E. S. (2013). Melting lizards and crying mailboxes:

Children's preferential recall of minimally counterintuitive concepts. Cognitive Science, 37(7), 1251-1289. https://doi.org/10.1111/cogs.12037

Barlev, M., \& Shtulman, A. (2021). Minds, bodies, spirits, and gods: Does widespread belief in disembodied beings imply that we are inherent dualists? Psychological Review, 128(6), 1007-1021. https://doi.org/10.1037/rev0000298

Baron-Cohen, S., \& Wheelwright, S. (2004). The Empathy Quotient: An Investigation of Adults with Asperger Syndrome or High Functioning Autism, and Normal Sex Differences. Journal of Autism and Developmental Disorders, 34(2), 163-175. https://doi.org/https://doi.org/10.1023/B:JADD.0000022607.19833.00

Baron-Cohen, S., Wheelwright, S., Hill, J., Raste, Y., \& Plumb, I. (2001). The "Reading the Mind in the Eyes" Test Revised Version: A Study with Normal Adults, and Adults with Asperger Syndrome or High-functioning Autism. Journal of Child Psychology and Psychiatry, 42(2), 241-251. http://dx.doi.org/10.1111/1469-7610.00715

Barrett, J. L. (2000). Exploring the natural foundations of religion. Trends in Cognitive Science, 4, 29-34. https://doi.org/10.1016/S1364-6613(99)01419-9

Barrett, J. L. (2004). Why Would Anyone Believe in God? In Cognitive science of religion series. AltaMira Press.

Barrett, J. L. (2008). Why Santa Claus is Not a God. Journal of Cognition and Culture, 8(1), 149-161. https://doi.org/10.1300/J095v03n01_07

Barrett, J. L., Burdett, E. R., \& Porter, T. J. (2009). Counterintuitiveness in Folktales: Finding the Cognitive Optimum. Journal of Cognition and Culture, 9, 271-287. https://doi.org/10.1163/156770909X12489459066345 
Barrett, J. L., \& Keil, F. C. (1996). Conceptualizing a Nonnatural Entity: Anthropomorphism in God Concepts. Cognitive Psychology, 31(3), 219-247. https://doi.org/10.1006/cogp.1996.0017

Barrett, J. L., \& Nyhof, M. A. (2001). Spreading nonnatural concepts. Journal of Cognition and Culture, 1, 69-100. https://doi.org/10.1163/156853701300063589

Bering, J. M., \& Bjorklund, D. F. (2004). The natural emergence of reasoning about the afterlife as a developmental regularity. Developmental Psychology, 40(2), 217-233. https://doi.org/10.1037/0012-1649.40.2.217

Bloom, P. (2005). Descarte's Baby: How the Science of Child Development Explains What Makes Us Human. Basic Books.

Bloom, P. (2007). Religion is natural. Developmental Science, 10(1), 147-151. https://doi.org/10.1111/j.1467-7687.2007.00577.x

Boyer, P. (1994). Naturalness of Religious Ideas: a cognitve theory of religion. University of California Press.

Boyer, P. (2001). Religion Explained. Basic Books.

Boyer, P. (2008). Religion: Bound to believe? Nature, 455, 1038-1039.

Boyer, P., \& Liénard, P. (2007). Why ritualized behavior? Precaution Systems and action parsing in developmental, pathological and cultural rituals. Behavioral and Brain Sciences, 29(06), 1-56. https://doi.org/10.1017/S0140525X06009332

Boyer, P., \& Ramble, C. (2001). Cognitive templates for religious concepts: cross-cultural evidence for recall of counter-intuitive representations. Cognitive Science, 25, 535-564. https://doi.org/10.1207/s15516709cog2504_2

Carey, S. (2009). The Origin of Concepts. Oxford Univeristy Press.

Chalmers, D. J. (1996). The conscious mind: In search of a fundamental theory. Oxford 
Paperbacks.

Chudek, M., McNamara, R. A., Birch, S., Bloom, P., \& Henrich, J. (2018). Do minds switch bodies? Dualist interpretations across ages and societies. Religion, Brain and Behavior, 8(4), 354-368. https://doi.org/10.1080/2153599X.2017.1377757

Cohen, E., \& Barrett, J. L. (2008). Conceptualizing Spirit Possession: Ethnographic and Experimental Evidence. Ethos, 36(2), 246-267. https://doi.org/10.1111/j.15481352.2008.00013

Csibra, G., Gergely, G., Biro, S., Koós, O., \& Brockbank, M. (1999). Goal attribution without agency cues: the perception of "pure reason" in infancy. Cognition, $72,237 \pm 267$. https://doi.org/10.1016/S0010-0277(99)00039-6

Damasio, A. (1994). Descartes' Error: Emotion, Reason and the Human Brain. Putnam.

Epley, N., Waytz, A., Akalis, S., \& Cacioppo, J. T. (2008). When we need a Human:

Motivational Determinants of Anthropomorphism. Social Cognition, 26, 143-155. https://doi.org/10.1521/soco.2008.26.2.143

Feuerbach, L. (1841). The Essence of Christianity. Harper \& Row.

Fodor, J. A. (1983). The modularity of mind. MIT press.

Galbraith, P. W. (2019). Otaku and the Struggle for Imagination in Japan. Duke University Press.

Gervais, W. M. (2013). Perceiving Minds and Gods. Perspectives on Psychological Science, 8(4), 380-394. https://doi.org/10.1177/1745691613489836

Gervais, W. M., \& Henrich, J. (2010). The Zeus Problem: Why Representational Content Biases Cannot Explain Faith in Gods. Journal of Cognition and Culture, 10, 383-389. https://doi.org/10.1163/156853710X531249

Gervais, W. M., Willard, A. K., Norenzayan, A., \& Henrich, J. (2011). The Cultural 
Transmission Of Faith: Why innate intuitions are necessary, but insufficient, to explain religious belief. Religion, 41(3). https://doi.org/10.1080/0048721X.2011.604510 Gibbon, J. (2008). God is great, God is good: Teaching god concepts in Turkish Islamic sermons. Poetics, 36(5-6), 389-403. https://doi.org/10.1016/j.poetic.2008.06.009

Guthrie, S. E. (1980). A cognitive theory of religion. Current Anthropology, 21(2), 181-203. http://dx.doi.org/10.1086/202429

Guthrie, S. E. (1993). Faces in the Clouds: A New Theory of Religion. Oxford University Press. Guthrie, S. E. (1996). Religion: What Is It? Journal for the Scientific Study of Religion, 35(4), 412-419. https://doi.org/10.2307/1386417

Haselton, M. G., \& Buss, D. M. (2000). Error Management Theory: A New Perspective on Biases in Cross-Sex Mind Reading. Journal of Personality and Social Psychology, 78(1), 81-91. https://doi.org/10.1037/0022-3514.78.1.81

Huffpost. (2017). Dog Butt Looks Like Jesus Christ In A Robe (PHOTO).

https://www.huffpost.com/entry/dog-butt-looks-like-jesus-photo_n_3436086 Hume, D. (1779). Dialogues Concerning Natural Religion. Bobbs-Merrill. Jack, A. I. (2016). Why Do You Believe in God? Relationships between Religious Belief, Analytic Thinking, Mentalizing and Moral Concern. 1-21. https://doi.org/10.1371/journal.pone.0155283

Jack, A. I., Dawson, A. J., Begany, K. L., Leckie, R. L., Barry, K. P., Ciccia, A. H., \& Snyder, A. Z. (2013). fMRI reveals reciprocal inhibition between social and physical cognitive domains. Neurolmage, 66(C), 385-401. https://doi.org/10.1016/j.neuroimage.2012.10.061 Kelemen, D. (1999a). Function, goals and intention: children's teleological reasoning about objects. Trends in Cognitive Sciences, 3(12), 461-468. https://doi.org/10.1016/S1364- 
6613(99)01402-3

Kelemen, D. (1999b). The scope of teleological thinking in preschool children. Cognition, 70(3), 241-272. https://doi.org/10.1016/S0010-0277(99)00010-4

Kelemen, D. (2004). Are Children "Intuitive Theists"? Reasoning about purpose and design in nature. Psychological Science, 15(5), 295-301. https://doi.org/10.1111/j.09567976.2004.00672.x

Kelemen, D., \& Rosset, E. (2009). The Human Function Compunction: Teleological explanation in adults. Cognition, 111(1), 138-143.

https://doi.org/10.1016/j.cognition.2009.01.001

Kelemen, D., Rottman, J., \& Seston, R. (2013). Professional physical scientists display tenacious teleological tendencies: Purpose-based reasoning as a cognitive default. Journal of Experimental Social Psychology. https://doi.org/10.1037/a0030399

Kirkpatrick, L. A. (1999). Toward an Evolutionary Psychology of Religion and Personality. Journal of Personality, 67(6), 921-952. https://doi.org/10.1111/1467-6494.00078 Lawson, E. T., \& McCauley, R. N. (1990). Rethinking Religion: Connecting Cognition and Culture. Cambridge University Press.

Leslie, A. M. (1994). ToMM, ToBy, and Agency: Core architecture and domain specificity. In L. A. Hirschfeld \& S. A. Gelman (Eds.), Mapping the mind: Domain specificity in cognition and culture. Cambridge University Press.

Lewis, I. M. (2003). Ecstatic Religion: A Study of Shamanism and Spirit Possession. Routledge. Lillard, A. S. (1997). Other Folk's Theories of Mind and Behavior. Psychological Science, 8(4), 268-274. https://doi.org/10.1111/j.1467-9280.1997.tb00437.x

Lillard, A. S. (1998). Ethnopsychologies: Cultural variations in theories of mind. Psychological Bulletin, 123(1), 3-32. https://doi.org/10.1037/0033-2909.123.1.3 
Lindeman, M., Svedholm-Häkkinen, A. M., \& Lipsanen, J. (2015). Ontological confusions but not mentalizing abilities predict religious belief, paranormal belief, and belief in supernatural purpose. Cognition, 134(C), 63-76.

http://dx.doi.org/10.1016/j.cognition.2014.09.008

Lisdorf, A. (2004). The Spread of Non-Natural Concepts. Journal of Cognition and Culture, 4, 151-173. https://doi.org/10.1163/156853704323074796

Lisdorf, A. (2007). "What's HIDD'n in the HADD?". Journal of Cognition and Culture, 7(3), 341-353. https://doi.org/10.1163/156853707X208549

Lombrozo, T., Kelemen, D., \& Zaitchik, D. (2007). Inferring Design Evidence of a Preference for Teleological Explanations in Patients With Alzheimer's Disease. Psychological Science, 18, 11. https://doi.org/10.1111/j.1467-9280.2007.02015.x

Luhrmann, T. M. (2012). When God talks back: Understanding the American evangelical relationship with God. Knopf.

McNamara, R. A., Willard, A. K., Norenzayan, A., \& Henrich, J. (2019). Weighing outcome vs. intent across societies: How cultural models of mind shape moral reasoning. Cognition, 182. https://doi.org/10.1016/j.cognition.2018.09.008

Norenzayan, A., Atran, S., Faulkner, J., \& Schaller, M. (2006). Memory and mystery: The cultural selection of minimally counterintuitive narratives. Cognitive Science, 30(3), $531-553$.

Norenzayan, A., Gervais, W. M., \& Trzesniewski, K. H. (2012). Mentalizing Deficits Constrain Belief in a Personal God. PLoS ONE, 7(5), e36880.

http://dx.doi.org/10.1371\%2Fjournal.pone.0036880

Paley, W. (1802). Natural Theology or Evidences of the Existence and Attributes of the Deity. Oxford University Press. 
Purzycki, B. G. (2013). Toward a Cognitive Ecology of Religious Concepts: Evidence from the Tyva Republic. Journal for the Cognitive Science of Religion, 1(1), 99-120. https://doi.org/10.1558/jcsr.v1i1.99

Purzycki, B. G., \& McNamara, R. A. (2016). An Ecological Theory of Gods' Minds. In H. De Cruz \& R. Nichols (Eds.), Advances in Religion, Cognitive Science, and Experimental Philosophy (pp. 143-167). Continuum.

Purzycki, B. G., \& Willard, A. K. (2016). MCl theory: a critical discussion. Religion, Brain \& Behavior, 6(3), 207-248. https://doi.org/10.1080/2153599X.2015.1024915

Richert, R. A., \& Harris, P. L. (2008). Dualism revisited: Body vs. mind vs. soul. Journal of Cognition and Culture, 8(1-2), 99-115. https://doi.org/10.1163/156770908X289224

Richert, R. A., Saide, A. R., Lesage, K. A., \& Shaman, N. J. (2017). The role of religious context in children's differentiation between God's mind and human minds. British Journal of Developmental Psychology, 35(1), 37-59. https://doi.org/10.1111/bjdp.12160

Rottman, J., Zhu, L., Wang, W., Seston Schillaci, R., Clark, K. J., \& Kelemen, D. (2017). Cultural influences on the teleological stance: evidence from China. Religion, Brain \& Behavior, 7(1), 17-26. https://doi.org/10.1080/2153599X.2015.1118402

Shtulman, A. (2008). Variation in the Anthropomorphization of Supernatural Beings and Its Implications for Cognitive Theories of Religion. Journal of Experimental Psychology: Learning Memory and Cognition, 34(5), 1123-1138. https://doi.org/10.1037/02787393.34.5.1123

Singh, M. (2018). The cultural evolution of shamanism. Behavioral and Brain Sciences, e66, 1-62. https://doi.org/10.1017/S0140525X17001893

Singh, M. (2019). Magic, explanations, and evil: On the origins and design of witches and sorcerers. Current Anthropology, August 2018. https://doi.org/10.31235/osf.io/pbwc7 
Slingerland, E., \& Chudek, M. (2011). The Prevalence of Mind-Body Dualism in Early China. Cognitive Science, 35(5), 997-1007.

Sørensen, J. (2005). Religion in Mind : A Review Article of the Cognitive Science of Religion. Numen, 52(4), 465-494.

Sperber, D. (1996). Explaining culture: A naturalistic approach. Blackwell Publishers.

Tremoulet, P. D., \& Feldman, J. (2000). Perception of animacy from the motion of a single object. Perception, 29(8), 943-951. https://doi.org/10.1068/p3101

Tylor, E. D. (1871). Primitive culture: Researches into the development of mythology, philosophy, religion, art, and custom. Gordon Press.

Upal, M. A. (2010). An alternative account of the minimal counterintuitiveness effect. Cognitive Systems Research, 11(2), 194-203.

Upal, M. A., Gonce, L. O., Tweney, R. D., \& Slone, D. J. (2007). Contextualizing Counterintuitiveness: How Context Affects Comprehension and Memorability of Counterintuitive Concepts. Cognitive Science, 31(3), 415-439. http://dx.doi.org/10.1080/15326900701326568

Visuri, I. (2012). Could Everyone Talk to God? A Case Study on Asperger's Syndrome, Religion, and Spirituality. Journal of Religion, Disability and Health, 16(4), 352-378. https://doi.org/10.1080/15228967.2012.731888

Visuri, I. (2018). Rethinking autism, theism, and atheism. Archive for the Psychology of Religion, 40(1), 1-31. https://doi.org/10.1163/15736121-12341348

Visuri, I. (2020). Sensory supernatural experiences in autism. Religion, Brain and Behavior, 10(2), 151-165. https://doi.org/10.1080/2153599X.2018.1548374

Watson-Jones, R. E., Busch, J. T. A., Harris, P. L., \& Legare, C. H. (2016). Does the Body Survive Death? Cultural Variation in Beliefs About Life Everlasting. Cognitive Science, 
41, 455-476. http://doi.wiley.com/10.1111/cogs.12430

Waytz, A., Morewedge, C. K., Epley, N., Monteleone, G., Gao, J.-H., \& Cacioppo, J. T. (2010). Making sense by making sentient: Effectance motivation increases anthropomorphism. Journal of Personality and Social Psychology, 99(3), 410-435.

https://doi.org/https://doi.org/10.1037/a0020240

White, C. (2021). An Introduction to the Cognitive Science of Religion: Connecting Evolution, Brain, Cognition, and Culture. Routledge.

White, C. J. M., Baimel, A., \& Norenzayan, A. (2021). How cultural learning and cognitive biases shape religious beliefs. Current Opinion in Psychology, 40, 34-39. https://doi.org/10.1016/j.copsyc.2020.07.033

White, C. J. M., Willard, A. K., Baimel, A., \& Norenzayan, A. (2021). Cognitive Pathways to Belief in Karma and Belief in God. Cognitive Science, 45(1). https://doi.org/10.1111/cogs.12935

Whitehouse, H. (2004). Modes of religiosity: A cognitive theory of religious transmission. AltaMira Press.

Whitehouse, H. (2021). The ritual animal: Imitation and cohesion in the evolution of social complexity. Oxford University Press.

Willard, A. K. (2017). Agency detection is unnecessary in the explanation of religious belief. Religion, Brain \& Behavior, 38, 1-3. https://doi.org/10.1080/2153599X.2017.1387593

Willard, A. K., Cingl, L., \& Norenzayan, A. (2020). Cognitive Biases and Religious Belief: A Path Model Replication in the Czech Republic and Slovakia With a Focus on Anthropomorphism. Social Psychological and Personality Science, 11(1). https://doi.org/10.1177/1948550619841629

Willard, A. K., Henrich, J., \& Norenzayan, A. (2016). Memory and Belief in the Transmission 
of Counterintuitive Content. Human Nature, 1-23. http://dx.doi.org/10.1007/s12110016-9259-6

Willard, A. K., \& McNamara, R. A. (2019). The Minds of God(s) and Humans: Differences in Mind Perception in Fiji and North America. Cognitive Science, 43(1).

https://doi.org/10.1111/cogs.12703

Willard, A. K., \& Norenzayan, A. (2013). Cognitive biases explain religious belief, paranormal belief, and belief in life's purpose. Cognition, 129(2), 379-391.

https://doi.org/10.1016/j.cognition.2013.07.016

Xu, F., Spelke, E. S., \& Goddard, S. (2005). Number sense in human infants. Developmental Science, 8(1), 88-101. http://dx.doi.org/10.1111/j.1467-7687.2005.00395.x 